\title{
Incongruence between the Preferred Mode of Delivery and Risk of Childbirth Complications among Antepartum Women in Mulago Hospital, Uganda
}

\author{
Dan Kabonge Kaye ${ }^{1 *}$, Annettee Nakimuli ${ }^{1}$, Othman Kakaire ${ }^{1}$, Michael Odongo Osinde $^{2}$, \\ Nelson Kakande ${ }^{3}$, Scovia Nalugo Mbalinda ${ }^{4}$ \\ ${ }^{1}$ Department of Obstetrics and Gynecology, School of Medicine, College of Health Sciences, Makerere \\ University, Kampala, Uganda \\ ${ }^{2}$ Department of Obstetrics and Gynecology, Jinja Regional Hospital, Jinja, Uganda \\ ${ }^{3}$ Clinical, Operations and Health Services Research Program, Joint Clinical Research Centre, Kampala, Uganda \\ ${ }^{4}$ Department of Nursing, School of Health Sciences, College of Health Sciences, Makerere University, Kampala, \\ Uganda \\ Email: dankkaye@yahoo.com, annettee.nakimuli@gmail.com, kakaireothman@gmail.com, \\ omoggg@yahoo.com, kakandeivan@yahoo.com, snmbalinda@gmail.com
}

Received 19 August 2014; revised 15 September 2014; accepted 10 October 2014

Copyright (C) 2014 by authors and Scientific Research Publishing Inc.

This work is licensed under the Creative Commons Attribution International License (CC BY). http://creativecommons.org/licenses/by/4.0/

(c) (i) Open Access

\begin{abstract}
Objective: Women's preferences for the mode of delivery provide clues on their knowledge and perceptions of anticipated risk of childbirth complications. The objective was to investigate incongruence between preferred mode of delivery and risk of adverse pregnancy outcomes. Methods: Through a cross-sectional study, data were collected from 327 women admitted to Mulago hospital. Data included socio-demographic characteristics, past medical, gynaecological and obstetric history, pregnancy complications, knowledge of pregnancy complications and preferred mode of delivery. The preferred mode of delivery and knowledge of related risks for adverse pregnancy outcomes were compared. Results: The mean age of participants was 24.7 years $( \pm 5.9)$, ranging 14 - 43 years, of whom $41.4 \%$ were nulliparous. The preferred mode of delivery was vaginal $(84.1 \%)$. Incongruence (preference for a mode of delivery that did not correspond to expected or anticipated risks) occurred in $88(26.9 \%)$ of the women, and was associated with having secondary school or higher level of education (OR 2.49, CI 1.52 - 4.08) and history of previous vaginal delivery (OR 3.82, CI 1.94 - 7.49). Conclusion: One in four women had incongruence between preferred mode of delivery and risks of adverse pregnancy outcomes, which called for urgent interventions to improve decision-making about intrapartum care.
\end{abstract}

*Corresponding author.

How to cite this paper: Kaye, D.K., Nakimuli, A., Kakaire, O., Osinde, M.O., Kakande, N. and Mbalinda, S.N. (2014) Incongruence between the Preferred Mode of Delivery and Risk of Childbirth Complications among Antepartum Women in Mulago Hospital, Uganda. Open Journal of Obstetrics and Gynecology, 4, 889-898. http://dx.doi.org/10.4236/ojog.2014.414125 


\section{Keywords}

\section{Quality of Care, Intrapartum Care, Preference for Mode of Delivery, Decision-Making}

\section{Introduction}

The preferred mode of delivery is a critical consideration in making a birth plan, particularly to ensure that there is alignment between anticipated risks and the preferred mode of delivery [1]. The American College of Obstetricians and Gynaecologists (ACOG) [2] approves caesarean delivery on request, and recommends that a healthcare provider should consider, in addition, individuals' specific risks factors such as age, body mass index, gestation age and future reproductive plans. Caesarean delivery on maternal request is defined as a primary prelabor caesarean delivery in the absence of obstetric maternal or fetal indications [2]. While healthcare providers have an ethical obligation to consider the needs of their clients/patients, they have a moral duty to society to ensure equity and equitable allocation of healthcare resources [3] [4].

The World Health Organization guidelines, however, do not recommend caesarean section on request, but indicate that individuals may request caesarean delivery in cases of poor past obstetrics outcomes, anxiety about the birth process or history of traumatic birth, but cost of the preferred mode of delivery and the cultural context should be considered [1]. The International Federation of Gynaecology and Obstetrics [3] recommends that performing caesarean delivery for non-obstetric reasons is not justifiable, considering that caesarean delivery consumes more healthcare resources than vaginal deliveries. Additionally, such deliveries might create inequity by making it difficult for deserving women to access the life-saving operation [3]. Since the operation has risks for the mother and baby [5] [6], FIGO recommends performing caesarean section only for absolute obstetric indications [3].

Preference for caesarean section on request is associated with fear of labour, unpleasant previous childbirth experiences, wrong attitudes towards delivery, misconceptions, and worries about safety for both mother and child during delivery [7]-[16]. Yet some women refuse caesarean delivery even when it is indicated, due to the strong negative attitudes towards caesarean delivery [11] [15]-[19]. It is unclear what factors motivate women's preferred mode of delivery or whether such preferences are made with awareness of related risks of adverse pregnancy outcomes. Likewise, whether there is incongruence between the preferred mode of delivery and anticipated risk for adverse pregnancy outcomes is not documented. Such information would inform interventions for health education during pregnancy on birth preparedness.

\section{Materials and Methods}

This research was part of a post-doctoral research project of the first author (DKK) entitled Evaluation and surveillance of the impact of maternal and neonatal near-miss morbidity on the health of mothers and infantsin Jinja and Mulago hospital. The aim of this project is toassess preventable factors associated with maternal and neonatal morbidity and mortality.

\subsection{Theoretical Framework}

The theory of planned behaviour was employed to analyse the incongruence in preferences for mode of delivery and associated risks. This theory suggests that a person's behavior is determined by his/her intention to perform the behavior and that this intention is, in turn, a function of his/her attitude toward the behavior and his/her subjective norms. The theories surmise that behavioral achievement depends on both motivation (intention) and ability (behavioral control). Accordingly, the best predictor of behaviour (in this case choice of a preferred mode of delivery) is intention. Intention is defined as the cognitive representation of a person's readiness to perform a given behaviour. Intention itself depends on attitude toward the specific behavior, individual subjective norms and individual's perceived behavioural control. The theory assumes that only specific attitudes toward the behavior in question can be expected to predict an individual's behaviour. In addition to measuring attitudes toward the behavior, one needs to measure individuals' subjective norms. Subjective norms refer to individuals' beliefs about the behaviour. To predict someone's intentions requires evaluation of these beliefs and attitudes. 
Perceived behavioural control refers to people's perceptions of their ability to perform a given behaviour, and is assumed to influence individuals' intentions.

\subsection{Study Setting and Participants}

The study was conducted at Mulago hospital, Uganda's national referral hospital and the teaching hospital for Makerere University. It has over 1500 beds, of which over 400 are maternity beds, and conducts over 35,000 deliveries per year. Participants were 345 eligible participants who were women admitted to Mulago hospital due to complications of pregnancy, between 30 and 38 weeks of gestation. They were approached and requested to participate in the study during their hospitalization, from March 1 to November 30, 2013.

\subsection{Data Collection and Management}

Data was collected from 327 consecutively-recruited participants using an interviewer-administered questionnaire. (Eighteen women declined to participate: acceptance rate was 94.8\%). The questionnaire covered sociodemographic characteristics, medical, gynaecological and obstetric history, pregnancy complications, and knowledge of three risks, benefits and indications for vaginal or caesarean delivery. The questionnaire included questions on behavioural beliefs, subjective norms (that assess normative beliefs, motivation to comply), perceived behaviour control, past behaviour and behavioural intention.

The risks for delivery, evaluated from socio-demographic characteristics, obstetric history and history of present pregnancy, were compared with the preferred mode of delivery to assess incongruence. Incongruence was defined as a preferred mode of delivery that was not commensurate or compatible with expected risks/benefits to the mother or baby. Circumstances where a mother ideally could have a vaginal delivery but preferred a caesarean delivery and where the mother ideally required an elective caesarean section but preferred vaginal delivery constituted incongruence between preferred mode of delivery and expected risk or benefits. We assessed the association between incongruence and socio-demographic characteristics and reproductive factors. Stata software version 12 was used for data analysis, to estimate the odds ratios for selected socio-demographic characteristics and reproductive factors in predicting incongruence, at the $95 \%$ significance level.

\subsection{Ethical Considerations}

Ethical approval to conduct the study was obtained from the Ethics and research committees of Mulago hospital (REC 310-2012), the School of Medicine, Makerere University College of Health Sciences (REC 2012-172) and Uganda National Council for Science and Technology. Permission to conduct the study was obtained from the department of Obstetrics and Gynaecology, Makerere University. All participants gave written informed consent to be interviewed and were provided with counselling on mode of delivery.

\section{Results}

Table 1 shows the socio-demographic characteristics of the participants. The mean age of participants was 28.7 years ( \pm 4.9 ), range 14 - 41 years, of whom $41.4 \%$ were nulliparous. Table 2 shows the preferences for mode of delivery and reasons for such preferences. Of the 327 women, 275 (84.1\%) preferred vaginal delivery. The main reasons cited for preferring vaginal delivery were that it was the natural way of delivery and it was safer for the mother and the baby (for $26.8 \%$ and $22.0 \%$ respectively) and a positive experience on previous vaginal delivery (39.8\%). The main reasons for preference for caesarean delivery were its being safer for the baby $29.8 \%$ and fear of vaginal delivery (29.8\%).

Table 3 shows the proportion of participants that reported at least 4 risks or benefits of caesarean section and vaginal delivery as well as 4 indications for caesarean delivery. The commonest indications were poor progress of labor, antepartum haemorrhage and fetal distress. The commonest risks of caesarean delivery reported were bleeding, infection, long hospitalization and cost, while the most common risks of vaginal delivery reported were labor pains, birth trauma and fetal distress. Table 4 shows factors associated with incongruence for mode of delivery. Incongruence on preferred mode of delivery was found among 88 women (26.9\%). It was associated with having secondary school or higher level of education (OR 2.49, CI $1.52-4.08$ ), parity of 2 or higher, (OR 3.42, CI 1.67 - 7.04), history of previous vaginal delivery (OR 3.82, CI $1.94-7.49$ ). 
Table 1. Distribution of respondents according to socio-demographic characteristics of women $(\mathrm{N}=327)$.

\begin{tabular}{lll}
\hline Variable & Number & Percentage \\
\hline
\end{tabular}

\section{Age (years)}

$\begin{array}{lcc}<20 & 7 & 2.1 \\ 20-29 & 184 & 56.3 \\ 30-39 & 128 & 39.1 \\ \geq 40 & 8 & 2.4\end{array}$

\section{Level of education}

No formal or primary education

Secondary education

College/university

\section{Marital status}

$\begin{array}{lcc}\text { Single } & 29 & 8.9 \\ \text { Married } & 261 & 81.2 \\ \text { Cohabiting } & 30 & 9.6 \\ \text { Divorced } & 2 & 0.3\end{array}$

\section{Occupation}

Employed/self employed

Peasant

House-wife

Students

\section{Gravidity}

$\begin{array}{lcc}\text { Primigravida } & 130 & 36.7 \\ \text { Gravida } 2-4 & 158 & 48.3 \\ \text { Gravida } 5 \text { and above } & 38 & 11.6\end{array}$

Past mode of delivery $(n=196)$

$\begin{array}{lcc}\text { Vaginal delivery only } & 132 & 67.3 \\ { }^{*} \text { Caesarean delivery only } & 40 & 20.4 \\ \text { Both vaginal and caesarean delivery } & 24 & 12.3\end{array}$

*Of these, 32 had an absolute indication for elective caesarean delivery. 
Table 2. Reasons for preference of vaginal or caesarean delivery.

\begin{tabular}{|c|c|c|}
\hline Reasons for preference & Number & $\%$ \\
\hline \multicolumn{3}{|l|}{ Preferred mode of delivery $(n=327)$} \\
\hline Vaginal delivery & 275 & 84.1 \\
\hline Caesarean delivery & 52 & 15.9 \\
\hline \multicolumn{3}{|l|}{$\Omega$ Reasons for preference of vaginal delivery $(n=275)$} \\
\hline Vaginal delivery is the natural way of delivery & 117 & 42.5 \\
\hline Vaginal delivery is safer for the baby & 164 & 59.6 \\
\hline Vaginal delivery has quicker post-delivery recovery & 156 & 56.7 \\
\hline Vaginal delivery is safer for the mother & 18 & 6.5 \\
\hline Vaginal delivery has less overall pain & 158 & 57.4 \\
\hline \multicolumn{3}{|l|}{$\Omega$ Reasons for preference of caesarean delivery $(n=52)$} \\
\hline Caesarean delivery is safer for the baby & 10 & 19.2 \\
\hline Fear of vaginal delivery & 36 & 69.2 \\
\hline Caesarean delivery has less overall pain & 15 & 28.8 \\
\hline Caesarean delivery has less vaginal trauma & 13 & 25.0 \\
\hline Caesarean delivery allows a better control of timing of birth & 12 & 35.5 \\
\hline Previous negative experience in previous vaginal deliveries, such as still birth or neonatal death & 18 & 34.6 \\
\hline Previous Caesarean delivery & 31 & 59.6 \\
\hline Caesarean section is safer for the baby if mother has HIV & 24 & 46.2 \\
\hline \multicolumn{3}{|l|}{$\Omega$ Experiences and perceptions of childbirth } \\
\hline * Positive experience on vaginal delivery & 130 & 83.3 \\
\hline * Negative experience on vaginal delivery & 33 & 21.2 \\
\hline$¥$ Positive experience of caesarean delivery & 12 & 18.8 \\
\hline$¥$ Negative experience of caesarean delivery & 28 & 43.8 \\
\hline$\infty$ Perceived positive experiences on caesarean delivery & 112 & 57.1 \\
\hline$\infty$ Perceived negative experiences on caesarean delivery & 12 & 6.1 \\
\hline$\alpha$ Negative perception of caesarean delivery, but no experience of such delivery & 220 & 94.8 \\
\hline$\beta$ Negative perception of vaginal delivery, but no experience of such delivery & 28 & 16.5 \\
\hline \multicolumn{3}{|l|}{$\Omega$ Whose responsibility for decision-making on mode of delivery $(n=327)$} \\
\hline Mothers & 259 & 79.2 \\
\hline Family members & 34 & 10.4 \\
\hline Spouses & 90 & 27.5 \\
\hline Health workers & 271 & 82.9 \\
\hline The mothers condition (obstetric indications) & 212 & 64.8 \\
\hline The unborn baby's condition & 120 & 36.7 \\
\hline The risks to the mother or baby mode of delivery & 230 & 70.3 \\
\hline
\end{tabular}

$\Omega$, Multiple responses were elicited; *, 156 participants; ¥, 64 participants; $\infty, 196$ participants; $\alpha, 232$ participants; $\beta$, 170 participants. 
Table 3. Knowledge of benefits and risks of preferred mode of delivery and congruence of preferred mode of delivery and anticipated risks $(\mathrm{N}=327)$.

\begin{tabular}{ccc}
\hline Variable & $\mathrm{N}$ & $\%$ \\
\hline Knowledge of 3 benefits of vaginal delivery & 129 & 39.4 \\
Knowledge of 3 risks of vaginal delivery & 36 & 11.2 \\
Knowledge of 3 benefits of caesarean delivery & 50 & 15.4 \\
Knowledge of 3 Indications of caesarean delivery & 148 & 45.4 \\
Knowledge of 3 risks of caesarean delivery & 114 & 34.9 \\
\hline Incongruence between anticipated risks and mode of delivery & 88 & 26.9
\end{tabular}

Table 4. Bivariate and multivariate analysis of factors associated with incongruence on preferred mode of delivery.

\begin{tabular}{|c|c|c|c|c|}
\hline Variable & $\begin{array}{c}\text { Congruence } \\
(\mathrm{N}=239) \mathrm{N}(\%)\end{array}$ & $\begin{array}{l}\text { No congruence } \\
(\mathrm{N}=88) \mathrm{N}(\%)\end{array}$ & $\begin{array}{l}\text { Bivariate analysis } \\
\text { OR }(95 \% \text { CI })\end{array}$ & $\begin{array}{c}\text { Multivariate analysis } \\
\text { OR }(95 \% \mathrm{CI})\end{array}$ \\
\hline \multicolumn{5}{|l|}{ Age (years) } \\
\hline$<20$ & $6(2.5)$ & $1(1.1)$ & 1 & 1 \\
\hline $20-29$ & $141(59.0)$ & $45(51.1)$ & $0.64(0.94-1.98)$ & $0.24(0.06-1.23)$ \\
\hline $30-39$ & $87(36.4)$ & 39 (44.35) & $0.99(0.35-2.81)$ & $0.22(0.05-1.05)$ \\
\hline$\geq 40$ & $5(2.1)$ & $3(3.4)$ & $0.74(0.26-2.09)$ & $0.28(0.04-1.81)$ \\
\hline \multicolumn{5}{|l|}{ Level of education } \\
\hline Primary and less & $74(30.9)$ & $13(14.8)$ & 1 & 1 \\
\hline Secondary and more & 165 (69.9) & $75(85.2)$ & $2.61(1.65-4.14)$ & $2.49(1.52-4.08)$ \\
\hline \multicolumn{5}{|l|}{ Parity } \\
\hline Nulliparous & $181(55.3)$ & $36(40.9)$ & 1 & 1 \\
\hline Parous women & 138 (44.7) & $52(59.1)$ & $1.38(1.06-1.81)$ & $1.89(1.17-3.07)$ \\
\hline \multicolumn{5}{|l|}{ Vaginal delivery prior } \\
\hline Absent & $163(68.2)$ & $36(40.9)$ & 1 & 1 \\
\hline Present & 76 (31.8) & $52(59.9)$ & $1.70(1.2-2.1)$ & $3.07(1.85-5.12)$ \\
\hline \multicolumn{5}{|l|}{ History of still birth } \\
\hline History of still birth & 96 & $69(78.4)$ & 1 & 1 \\
\hline No history of still birth & 231 & $19(26.4)$ & $0.36(0.29-0.44)$ & $0.68(0.47-0.92)$ \\
\hline \multicolumn{5}{|c|}{ History of caesarean delivery } \\
\hline No history & $64(19.6)$ & $58(65.9)$ & 1 & 1 \\
\hline Prior caesarean & $263(80.4)$ & $30(34.1)$ & $0.59(0.49-0.69)$ & $0.29(0.22-0.38)$ \\
\hline
\end{tabular}




\section{Discussion}

The study shows incongruence between risk of childbirth complications and preferred mode of delivery. In childbirth, the objective is a mother and newborn in good health with the least possible level of intervention compatible with safety [1]. During pregnancy, women should make a birth plan. This document contains information on reproductive health risks, pregnancy complications, planned mode of delivery, chosen place for delivery, anticipated material and financial costs during delivery and need for birth companions [1]. The preferred mode of delivery is a critical consideration in making a birth plan, particularly to ensure that there is alignment between anticipated risks and the preferred mode of delivery [1].

The study results suggest that health education given to pregnant women may be inadequate, to change knowledge and attitudes, considering that women have inadequate knowledge or negative attitudes of risks, benefits and indications mode of delivery. Therefore, healthcare professionals need to improve on health education provided to women. Many pregnant women may prefer caesarean to vaginal delivery for various nonmedical reasons, in spite of well known risks related to this decision for both mother and baby, which (risks) may not be apparent until subsequent pregnancies.

Each mode of delivery has inherent risks and benefits which all pregnant women should be aware of as they make their individual birth plans [1]-[5]. While vaginal delivery is cheaper, has less morbidity and has possibility of shorter duration of hospitalization (as compared to caesarean delivery), it may be complicated by stressful, painful and long labour, fetal distress, genital tears, risk of genital prolapsed or obstetric fistula formation and need for episiotomy [1]-[5]. In addition, there might be failure of delivery (due to maternal or fetal indications) ending in emergency caesarean or instrumental delivery [1]-[5]. In contrast, advantages of elective caesarean section (on maternal request) include avoidance of labour pains and postterm pregnancy, easy planning for timing and place of delivery, easier arrangement for a birth companion, and lower risk of fetal distress, birth asphyxia or birth trauma [3] [4]. However, caesarean delivery is expensive compared to vaginal delivery, necessitates longer hospitalization, is associated with more morbidity and increases risk for urinary tract infection, urinary bladder and other tissue injury during operation, pulmonary embolism and anesthestic complications [1][5]. Furthermore, there is associated risk of long-term complications such as adhesion formation, incision hernia, uterine scar dehiscence (in future pregnancies), adherent placenta and placenta previa [1]-[5]. Caesarean delivery may be associated (in subsequent pregnancies) with delayed conception, increased risk of ectopic pregnancy, preterm birth and uterine scar dehiscence or rupture [20].

The implications of the study findings are that women must be provided with adequate information about risks and benefits of modes of delivery to enable them make informed choices. While caesarean delivery may reduce risks associated with vaginal delivery, these are replaced with those of caesarean delivery [21]. However, emergency caesarean deliveries may be more hazardous than elective procedures [2] [3] [21] such that it may be safer for mothers to receive elective caesarean section than to attempt vaginal birth [2] [3] [20]-[22], particularly where the likelihood of achieving vaginal birth is minimal, unguaranteed or unsafe, such as poor obstetric history [2] [3] [20]-[22]. It is difficult to predict which women will have a successful vaginal birth after one caesarean delivery [2] [3] [20]-[22]. While emergency caesarean sections almost double the risk associated with elective caesarean sections [21] [22], instrumental vaginal deliveries portend higher risk than elective caesarean section [21] [22]. Silver et al. [23] found placenta accretain $0.24 \%, 0.31 \%, 0.57 \%, 2.1 \%, 2.3 \%$ and $6.7 \%$ of women undergoing their first, second, third, fourth, fifth, and sixth or more caesarean deliveries, respectively, which was attributed to both increasing incidence of placenta praevia with repeated caesarean sections and increased likelihood of placenta accreta where the placenta was located over the uterine scar. Other complications include adhesions [22] [23] and higher risk of neonatal death in a subsequent vaginal delivery [24] [25].

The findings have implications for healthcare providers. Firstly, women's awareness is not enough, as even women who were aware of risks related childbirth preferred a mode of delivery associated with risks. Secondly, every opportunity should be used to change women's negative perceptions and empower women make right choices about pregnancy and childbirth. Some women choose the mode of delivery when they are uninformed of the risks of the mode, without appreciating risks, safety or benefits. Thirdly, healthcare providers should discourage caesarean section on request, as many mothers are not aware of inherent risks. If after discussion the patient maintains a request for caesarean delivery, doctors may only make perform caesarean section when they have ascertained that patients understand the risks and benefits of the decision made. Information on risks and benefit markedly influences decision-making for mode of delivery, and should be given with care. For women 
with a prior caesarean delivery, failure to deliver vaginally might be experienced as a "significant loss" [25]. In contrast, women might prefer an elective caesarean delivery if informed of potential risk of vaginal birth, particularly after caesarean delivery, and thereby refuse a trial of labor or trial of scar even where they are indicated [26]. Likewise, preference for caesarean section may contribute to high caesarean section rates of questionable indications among low risk women, if patients' autonomy is the priority [2] [3] [9] [26]. Such scenario may eventually lead to inequity whereby women with clear indications for caesarean section fail to access the services [2] [3] [9] [26]. Caesarean sections of questionable indications contribute to unnecessary operations that drain resources for women who absolutely need the service, thereby contributing to inequity [27] [28]. Since caesarean requests arise from fear of childbirth, health workers should address factors that contribute to such fear of childbirth [29] [30]. Health workers should agree on patients' preference with caution [29]. Mothers are often not adequately involved in decision-making during intrapartum care [29]-[31] and often find it difficult to make informed decision for mode of delivery [32] [33].

The study's limitations arise from the limitations of the theory of planned behaviour. The theory assumes that individuals have opportunities and resources to enable successful performance of the desired behaviour (choice of mode of delivery), regardless of the intention. The theory fails to address variables that factor into behavioral intention and motivation (threats, past experience or mood). Though normative influences are assessed, the theory does fully assess environmental or economic factors that influence one's intention to execute a behavior. Lastly, decision-making is not a linear process, but can change over time.

\section{Conclusion}

In conclusion, women may make decisions on a mode of delivery that is not commensurate with risks or benefits. Healthcare providers should discuss with them risks and benefits of various birth options to enable them to make appropriate decisions.

\section{Acknowledgements}

This study was part of a post-doctoral research funded by SIDA through the Makerere University-Karolinska Institutet postdoctoral research grants.

\section{Conflict of Interest}

The authors declare that they have no conflict of interest.

\section{Authors' Contributions}

DKK conceptualized the study as part of his post-doctoral research project. OK, MOO, and NK advised on the design. DKK collected the data, led the analysis, and wrote the text of the paper. All the co-authors gave advice on the data analysis, presentation of the results. All co-authors reviewed and edited the text and approved the final manuscript.

\section{References}

[1] World Health Organization (1997) Care in Normal Birth: A Practical Guide. www.who.int/reproductive-health/publications/

[2] American College of Obstetricians and Gynecologists (2007) Caesarean Delivery on Maternal Request. ACOG Committee Opinion No. 394. Obstetrics and Gynecology, 110, 1501-1504.

[3] Schenker, J. and Cain, J. (1999) FIGO Committee Report: FIGO Committee for the Ethical Aspects of Human Reproduction and Women's Health. International Journal of Gynecology and Obstetrics, 64, 317-322.

[4] Schindl, M., Birner, P., Reingrabner, M., Joura, E., Husslein, P. and Langer, M. (2003) Elective Caesarean Section vs. Spontaneous Delivery: A Comparative Study of Birth Experience. Acta Obstetriciaet Gynecologia Scandinavica, 82, 834-840.

[5] Villar, J., Carroli, G., Zavaleta, N., Donner, A., Wojdyla, D. and Faundes, A. (2007) Maternal and Neonatal Individual Risks and Benefits Associated with Caesarean Delivery: Multicentre Prospective Study. British Medical Journal, 335, 1025-1029. http://dx.doi.org/10.1136/bmj.39363.706956.55 
[6] Zanardo, V., Simbi, A., Franzoi, M., Solda, G., Salvadori, A. and Trevisanuto, D. (2004) Neonatal Respiratory Morbidity Risk and Mode of Delivery at Term: Influence of Timing of Elective Caesarean Delivery. Acta Paediatricia, 93, 643-647.

[7] Weaver, J., Statham, H. and Richards, M. (2007) Are There "Unnecessary" Caesarean Sections? Perceptions of Women and Obstetricians about Caesarean Sections for Nonclinical Indications. Birth, 34, 32-41. http://dx.doi.org/10.1111/j.1523-536X.2006.00144.X

[8] Habiba, M., Kaminski, M., Da Frè, M., Marsal, K., Bleker, O., Librero, J., et al. (2006) Caesarean Section on Request: A Comparison of Obstetricians' Attitudes in Eight European Countries. BJOG: An International Journal of Obstetrics \& Gynaecology, 113, 647-665. http://dx.doi.org/10.1111/j.1471-0528.2006.00933.x

[9] Litorp, H., Kidanto, H., Nystrom, L., Darj, E. and Essén, B. (2013) Increasing Caesarean Section Rates among LowRisk Groups: A Panel Study Classifying Deliveries According to Robson at a University Hospital in Tanzania. BMC Pregnancy Childbirth, 13, 107. http://dx.doi.org/10.1186/1471-2393-13-107

[10] Druzin, M.L. and El-Sayed, Y.Y. (2006) Cesarean Delivery on Maternal Request: Wise Use of Finite Resources? A View from the Trenches. Seminars in Perinatology, 30, 305-358. http://dx.doi.org/10.1053/j.semperi.2006.07.012

[11] Hildingsson, I., Rådestad, I., Rubertsson, C., Rubertsson, C. and Waldenström, U. (2002) Few Women Wish to Be Delivered by Caesarean Section. BJOG: An International Journal of Obstetrics \& Gynaecology, 109, 618-623. http://dx.doi.org/10.1111/j.1471-0528.2002.01393.x

[12] Angeja, A., Washington, A., Vargas, J., Gomez, R., Rojas, I. and Caughey, A. (2006) Chilean Women’s Preferences Regarding Mode of Delivery: Which Do They Prefer and Why? BJOG: An International Journal of Obstetrics \& Gynaecology, 113, 1253-1258. http://dx.doi.org/10.1111/j.1471-0528.2006.01069.x

[13] Aziken, M., Omo-Aghoja, L. and Okonofua, F. (2007) Perception and Attitude of Pregnant Women towards Caesarean Section in Urban Nigeria. Acta Obstetricia et Gynecologia Scandinavica, 86, 42-47. http://dx.doi.org/10.1080/00016340600994950

[14] Gamble, J. and Creedy, D. (2001) Women's Preference for a Caesarean Section: Incidence and Associated Factors. Birth, 28, 101-110. http://dx.doi.org/10.1046/j.1523-536X.2001.00101.X

[15] Pang, M., Leung, T., Lau, T.K. and Chung, T.K.H. (2008) Impact of First Childbirth on Changes in Women's Preference for Mode of Delivery: Follow-Up of a Longitudinal Observational Study. Birth, 35, 121-128. http://dx.doi.org/10.1111/j.1523-536X.2008.00225.x

[16] Waldenström, U., Hildingsson, I., and Ryding, E. (2006) Antenatal Fear of Childbirth and Its Association with Subsequent Caesarean section and Experience of Childbirth. BJOG: An International Journal of Obstetrics \& Gynaecology, 113, 638-646. http://dx.doi.org/10.1111/j.1471-0528.2006.00950.x

[17] Chigbu, C. and Iloabachie, G. (2007) The Burden of Caesarean Section Refusal in a Developing Country Setting. BJOG: An International Journal of Obstetrics \& Gynaecology, 114, 1261-1265. http://dx.doi.org/10.1111/j.1471-0528.2007.01440.x

[18] Lavender, T., Hofmeyr, G.J., Neilson, J.P., Kingdon, C. and Gyte, G.M.L. (2007) Caesarean Section for Non-Medical Reasons at Term. Cochrane Database of Systematic Reviews. http://www.cochrane.org/reviews/en/ab004660.html

[19] Wax, J.R., Cartin, A., Michael, G. and Blackstone, J. (2004) Patient Choice Cesarean: An Evidence-Based Review. Obstetrical and Gynecological Survey, 59, 601-616. http://dx.doi.org/10.1097/01.OGX.0000133942.76239.57

[20] D’Souza, R. and Arulkumaran, S. (2013) To “C” or not to “C”? Caesarean Delivery upon Maternal Request: A Review of Facts, Figures and Guidelines. Journal of Perinatal Medicine, 41, 5-15.

[21] Allen, V.M., O’Connell, C.M., Liston, R.M. and Baskett, T.F. (2003) Maternal Morbidity Associated with Cesarean Delivery without Labor Compared with Spontaneous Onset of Labor at Term. Obstetrics and Gynecology, 102, 477482. http://dx.doi.org/10.1016/S0029-7844(03)00570-2

[22] Prior, E., Santhakumaran, S., Gale, C., Philipps, L.H., Modi, N. and Hyde, M.J. (2012) Breastfeeding after Cesarean Delivery: A Systematic Review and Meta-Analysis of World Literature. American Journal of Clinical Nutrition, 95, 1113-1135. http://dx.doi.org/10.3945/ajcn.111.030254

[23] Silver, R.M., Landon, M.B., Rouse, D.J., Leveno, K.J., Spong, C.Y., Thom, E.A., et al. (2006) Maternal Morbidity Associated with Multiple Repeat Cesarean Deliveries. Obstetrics and Gynecology, 107, 1226-1232. http://dx.doi.org/10.1097/01.AOG.0000219750.79480.84

[24] Walker, S.P., McCarthy, E.A., Ugoni, A., Lee, A., Lim, S. and Permezel, M. (2007) Cesarean Delivery or Vaginal Birth: A Survey of Patient and Clinician Thresholds. Obstetrics and Gynecology, 109, 67-72. http://dx.doi.org/10.1097/01.AOG.0000250902.67911.ce

[25] Smith, G.C., Pell, J.P., Cameron, A.D. and Dobbie, R. (2002) Risk of Perinatal Death Associated with Labor after Previous Caesarean Delivery in Uncomplicated Term Pregnancies. Journal of the American Medical Association, 287, 2684-2690. http://dx.doi.org/10.1001/jama.287.20.2684 
[26] Gibbons, J.M.B., Lauer, J.A., Betrán, A.P. and Althabe, F. (2010) The Global Numbers and Costs of Additionally Needed and Unnecessary Caesarean Sections Performed per Year: Overuse as a Barrier to Universal Coverage. Background Paper 30. World Health Organization, Geneva.

[27] Mancuso, A., De Vivo, A., Fanara, G., Settineri, S., Triolo, O. and Giacobbe, A. (2006) Women’s Preference on Mode of Delivery in Southern Italy. Acta Obstetriciaet Gynecologia Scandinavica, 85, 694-699. http://dx.doi.org/10.1080/00016340600645255

[28] Dweik, D., Girasek, E., Töreki, A., Mészáros, G. and Pál, A. (2014) Women’s Antenatal Preferences for Delivery Route in a Setting with High Cesarean Section Rates and a Medically Dominated Maternity System. Acta Obstetricia et Gynecologica Scandinavica, 93, 408-415. http://dx.doi.org/10.1111/aogs.12353

[29] Nerum, H., Halvorsen, L., Sørlie, T. and Øian, P. (2006) Maternal Request for Cesarean Section Due to Fear of Birth: Can It Be Changed through Crisis-Oriented Counseling? Birth, 33, 221-228. http://dx.doi.org/10.1111/j.1523-536X.2006.00107.x

[30] Little, M.O., Lyerly, A.D., Mitchell, L.M., Armstrong, E.M., Harris, L.H., Kukla, R. and Kuppermann, M. (2008) Mode of Delivery: Toward Responsible Inclusion of Patient Preferences. Obstetrics and Gynecology, 112, 913-918. http://dx.doi.org/10.1097/AOG.0b013e3181888fd8

[31] Thompson, R. and Miller, Y.D. (2014) Birth Control: To What Extent Do Women Report Being Informed and Involved in Decisions about Pregnancy and Birth Procedures? BMC Pregnancy and Childbirth, 14, 62. http://dx.doi.org/10.1186/1471-2393-14-62

[32] Moffat, M.A., Bell, J.S., Porter, M.A., Lawton, S., Hundley, V., Danielian, P., et al. (2007) Decision Making about Mode of Delivery among Pregnant Women Who Have Previously Had a Caesarean Section: A Qualitative Study. BJOG: An International Journal of Obstetrics \& Gynaecology, 114, 86-93. http://dx.doi.org/10.1111/j.1471-0528.2006.01154.x

[33] Deng, W., Klemetti, R., Long, Q., Wu, Z., Duan, C., Zhang, W.H., et al. (2014) Cesarean Section in Shanghai: Women's or Healthcare Provider's Preferences? BMC Pregnancy Childbirth, 14, 285. http://dx.doi.org/10.1186/1471-2393-14-285 
Scientific Research Publishing (SCIRP) is one of the largest Open Access journal publishers. It is currently publishing more than 200 open access, online, peer-reviewed journals covering a wide range of academic disciplines. SCIRP serves the worldwide academic communities and contributes to the progress and application of science with its publication.

Other selected journals from SCIRP are listed as below. Submit your manuscript to us via either submit@scirp.org or Online Submission Portal.
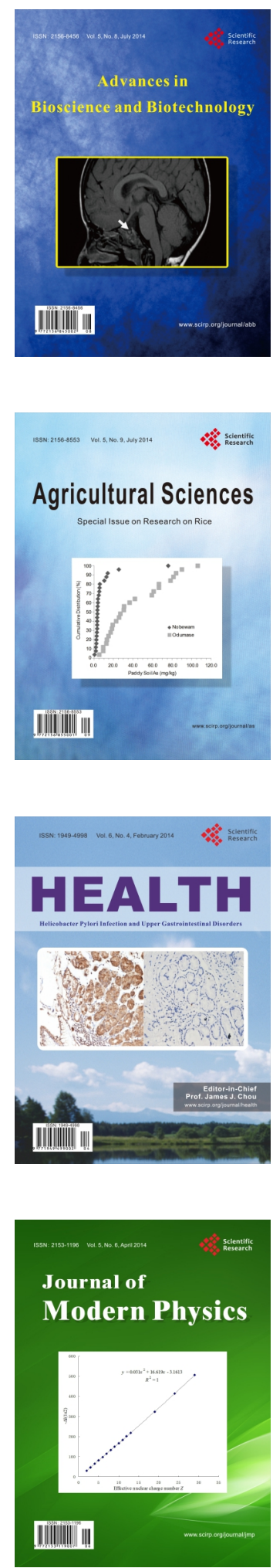
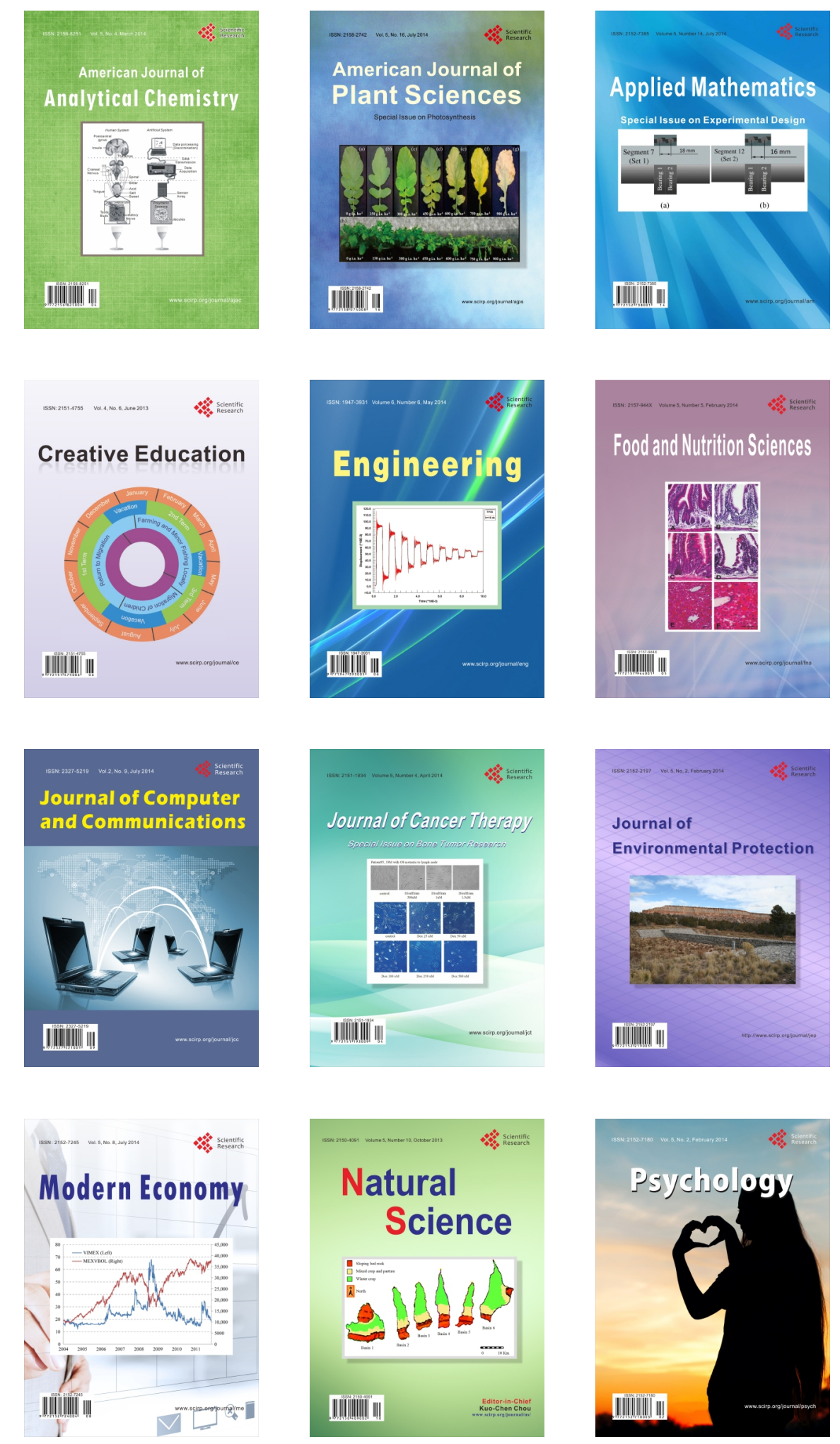